\title{
Who are our "Freuds"?A review of images in the history books of graphic design and their role in constructing a common vision about what graphic design is
}

abstract Alongside more in-depth historical analyses, a small number of illustrated global histories of graphic design have appeared in recent years. There are four fundamental authors who support the discipline's global message: Meggs, Eskilson, Drucker and Hollis. This paper sets out to scrutinize these works in search of archetypes. Since the works in question feature both visual and textual content, priority will be given to the visual. Considered a secondary (illustrative) message, it is more suitable for expressing personal tastes and beliefs, and is also important because design students are highly focused on graphics, which influences the formation of their visual culture. By reading these works as "picture" books, we can access layers of their message in which images provide clear information (artists'/creators' identities, nationalities, target clients, era, etc.). Thus we can understand part of the message by considering both the image and the intended effect on the reader. These metrics will highlight the type of clients or patrons present in the history of graphic design, the type and predominance of certain media, the designers' geographical origins, "school" affiliation and other relevant issues. Examining what the reader sees will expose different aspects of graphic design heritage and of what is seen as archetypal. While teacher/student contact and the students' visual environments greatly influence their development, we must also acknowledge that the images in these books will function as a reference for the shaping of a graphic designer's identity.

graphic design history, graphic design identity, graphic design history books, graphic design visual milestones

\section{Introduction}

Every discipline needs references: names and works that help define and shape the field, making it socially relevant. Graphic design is, by nature, a highly visual activity; thus, the formation of a visual culture is integral to a designer's development. There are few fully-illustrated global graphic design history reference books that contribute to this task. The four most commonly seen in university reading lists are "Meggs' History of Graphic Design", first published in 1983 and now in its fifth edition, (revised, since Megg's death in 2002, by Purvis); Hollis's "Concise History", first published in 1994 and revised for its 2001 second edition; Eskilson's "Graphic Design A New History" released in 2007, now in its second edition; and Drucker/McVarish's "Graphic Design History, A Critical Guide" from 2009 With so little literature addressing this issue globally, these works are naturally chosen to provide the aforementioned references for students and teachers on aspects such as key figures, milestones and reliable examples of excellence in graphic design.

The purpose of this paper is to understand the kind of visual message they convey and 
how it affects the construction of a collective image of the activity. The most recent edition of each book was used for the review.

\section{Reading the images in the books}

To better understand the message conveyed by the images - and only the images - some emotional distance was needed. So a grid analysis was used to collate some key elements for group scrutiny:

1. The medium used: posters, books (and for books, just the cover or the pages too?), magazines, tickets, etc. This tells us about the main graphic design mediums.

2. The size of the image and its position in the book. Size is important because even with fewer images, visual impact may be greater with full page reproductions.

3. Artists/Creators: We must keep track of whose work is featured and how often.

4. Nationality, important to help us understand the geography of the "global" histories. We have considered the client's nationality using Baxandall's idea (1991) of a "social fossil", because it encompasses the need for synergy between designer and client on many different levels. Therefore it seems more logical to consider the target country than the one where the designer was born.

5. Dates of the works used: these will provide some interesting insight into the periods featured. 6. Finally, this study also looked at the patrons' locations and professions, separating them to help pinpoint the most common type of patron.

\section{Book-by-book analysis}

\section{Hollis}

Hollis discusses 19 countries but only really focuses on eight; he allocates less than $1 \%$ to the remainder, except Japan (2.5\%). Since the book is structured by nationality, the weight of each country is more homogeneous, e.g. USA (17.4\%); Germany (16.8\%); United Kingdom (15.5\%); Switzerland (11.1\%).

We'll begin with the number of creators: Drucker features images from 258 creators (creators are not necessarily designers, although most are) in 341 pages (486 images), while Hollis features 846 images by 383 creators on much smaller pages (half the size of Drucker's). We can see that the weight of the images in this book is the lowest of all: $24.6 \%$. Meggs easily features the highest number of creators: 584 altogether, and 1,433 reproductions. Images account for almost $40 \%$ of the book.

While Meggs' book features the highest number of media categories (78), Hollis's is still impressive with 50 . Posters are clearly preferred, occupying $31 \%$ of the book's image space (27\% in Meggs, 36\% in Eskilson and 22\% in Drucker). Hollis's book reproduces posters in thumbnails.

As to the type of client, publishers are clearly in top place for Hollis, with a significant $39.7 \%$, followed by institutions (14.8\%) and services ( $9 \%$ ). Curiously, despite not being in the top 3, politics $(7.6 \%)$, the military $(6.6 \%)$ and art $(8.2 \%)$ have a significant presence in this book. At $8 \%$, the graphic industry dominates the space allocated to images, followed by the entertainment industry with $7 \%$.

The most heavily-featured designers are Bayer, Moholy-Nagy, El Lissitzky and Matter.

\section{Eskilson}

Of all the books analysed, this is the one that dedicates most space to images (48.21\%), presenting them in larger sizes. 
The fact that the narrative is built using a structure typical of art histories (Art nouveau, Dada, etc.) is noteworthy and is responsible for the wealth of "context images", i.e. images from other fields such as art and architecture. This also explains why Art appears as the third most cited "client" type (13.3\%), with institutions coming first (18.6\%) and publishers second (16\%).

The image/creator ratio is higher than in Drucker and relates to the fact that this book has fewer anonymous images ( $7 \%$ as against 34\%) and to there being more repetitions per creator (34\% of all the images are by 39 creators, each featured at least three times). The most-featured creators are van Doesburg (9), Behrens and Rand (8), and Bayer, Cassandre, El Lissitzky, Holwein and Tschichold (6).

Following the general trend, Eskilson mainly resorts to posters (184 out of 501 images), typography (11.6\%), corporate identity (5.39\%) and magazines (4.59\%). The geography covers the usual five countries: the United States with $29 \%$ of the book's image space, Germany with 22\%, England with $14 \%$ and France with $11 \%$. Surprisingly, Switzerland has a discreet presence (3\%) largely due to the significant presence (34.5\%) of Swiss design in the "International Style" chapter.

\section{Drucker/mcvarish}

In Drucker's book, 34\% of the images are anonymous; they create context. This scenario is mainly artistic, so if we remove the non-graphic design images we would lose $7 \%$ of the image space, $6 \%$ of which features artistic reproductions.

Drucker uses a restricted group of 23 items featuring graphic design. Posters dominate: there are 107 of them, followed by 91 books (18.7\%) out of a total of 486 reproductions, which means $40 \%$ of the book.

The geography focuses on 23 countries in total, but only three stand out: America, England and Germany with $30.48 \%, 18.54 \%$ and $12.08 \%$ of the image space respectively. American examples start appearing in chapter 6 (1660-1800) with an already generous presence (12.54\%), and then simply take over: $74.89 \%$ of the image space in $1930-1950$, $70.91 \%$ in $1950-1970$ and over 60\% thereafter. English images are particularly frequent from 1660 till 1920, occupying almost 50\% of the four chapters covering this period. Germany heads the "Innovation and Persuasion 1910-1930" chapter with 37\% of its images. Amazingly, France vanishes from 1930 onwards, with only a brief reappearance in the 1960-1970 chapter, accounting for 5.39\% of the images. Russia and Holland (2.78\% and 3.8\%) constitute the rest of the world. Not even Mariscal's revolutionary approach to Olympic Games pictograms is enough to earn Spain a mention in the book.

Bayer is the most-featured artist/creator in terms of reproductions, followed by Behrens, El Lissitzky and Lubalin.

\section{Meggs}

Meggs' book is probably the most popular. "The classic 'bible' of graphic design history", as the editors put it, a huge 6oo-page volume, is now in its 5 th edition. The last chapter, covering 1950 to the present, has 597 images, more than Drucker/McVarish's or Eskilson's entire books.

There are some quite unexplainable options, like the eight Dan Friedman images, occupying $300 \mathrm{~cm} 2$ : ten times more image area than Frutiger and much more than David 
Carson (3 entries, $265 \mathrm{~cm} 2$ ) or Milton Glaser ( 5 entries, $265 \mathrm{~cm} 2$ ). Friedman's work consists of one mock-up, one magazine cover and six graphical experiments (no client or purpose, just personal and educational items). $300 \mathrm{~cm} 2$ is almost as much as Portuguese design in its entirety. This indicates a history where designers themselves are the centre of attention with considerable focus on work done without clients or any commercial or social objective.

Once again Rand and El Lissitzky are the most-featured artists/creators with 20 reproductions each; but El Lissitzky surpasses Rand by far in terms of visual impact: 1,435 $\mathrm{cm} 2$ as against $868 \mathrm{~cm} 2$. Rand's visual impact is comparable to Tschichold and MoholyNagy. Bayer is the next most-featured creator with 16 entries covering $968 \mathrm{~cm} 2$.

Chapter 5 of this new edition includes 42 crammed pages on graphic design in the rest of the world: Japan, China, Holland and France each occupy over 1,000 cm2, which may sound like a lot but, to put it in perspective, the book's total image space occupies 108,856 $\mathrm{cm} 2$ ! Spain comes next ( $900 \mathrm{~cm} 2)$, followed by Poland $(818 \mathrm{~cm} 2)$ and Mexico $(760 \mathrm{~cm} 2)$. The number of posters in the gos and oos is amazing, bearing in mind that their use was very limited by then. It's almost like saying that even though posters do not make a huge social impact, they are the proper design medium.

\section{Conclusion: history books shaping identity}

All the books agree that graphic design's embryonic stage is to be found in the quest for alphabets, disappearing thereafter and resurfacing around the 10th century in medieval manuscripts. Gutenberg is seen as the next milestone, not so much for his design but for his technological invention, linking print technology to the identity of graphic design. Posters (another technological landmark), appear from the 19th century onwards.

It's not surprising to see that the history of design is a history made of "gourmet" objects (Fallan 2010, p. ix) and posters have this quality for their artistic impersonation. Shortly after Meggs first published his history we were warned that historians' preferences have little to do with the social life of the objects: "The history of design should not be confused with its present institutional and academic form, design history. The later by no means encompasses all of what the former might eventually become" (Dilnot 1989, p. 214). For example, we could look at the artists/creators occupying the most image space in the book and realize that graphic design's Freud, Jung and Pavlov are Herbert Bayer, Peter Behrens (amazingly, graphic design not being the most significant part of his work) and El Lissitzky. An unhealthy connection to art is also clearly identifiable, not only through the persistence of posters but in the structure of the book's message (Eskilson for example); undesirable state of affairs had already been pointed out: "The challenge, therefore, was to rescue the history of design from the margins of the modernist historiography's grand narratives of art, craft and architecture (...) and to create a new history (...) which would explore the boundaries of what design is and could be." (Whitehouse 2009, p.54) and the number of paintings featured in the books confirms it: Meggs' 4 th chapter has 49 entries from creators unconnected with graphic design: Picasso, Miró, Kandinsky, and 30 other famous artists/creators occupy more than 3,000 $\mathrm{cm} 2$, the same amount as graphic design from Japan, China, Holland and France combined. Also noteworthy is the featuring of well-known artists/creators doing fairly bland graphic design work, simply because of their status: "Andy Warhol did record covers". 
Walker (Walker 1989, p.33) can be extended to safe objects: art and design magazines used as examples of excellence but not men's magazines (although "Playboy" readers certainly outnumber Baseline ones). While excellence in book cover design might have little influence on Dan Brown's sales, shouldn't the impact on people and society be considered nevertheless? Do magazines about graphic design, conferences about graphic design and graphic design school brochures have such a big impact on people's lives or are we the central focus of our own history? We like to think that design targets improvement in other people's lives, but in our history these lives do not count.

Ads by Filippetti for Vespa, which hugely impacted Italian popular culture, are not shown but a Muller-Brockmann poster for a Beethoven concert in Zurich gets full coverage in every book.

ABC primers, admission tickets, album cards, almanacs, armed forces papers, train timetables, baggage stickers, beer and other alcohol labels and mats, billheads, birth certificates, board games, bonds, burial papers and dozens of other print ephemerae never make it to graphic design history. Only Drucker's book features bank notes - a meticulously-designed item of great significance to all of us for many years.

The books all prefer individuals to companies. Meggs' book, for example, features just 15 design companies in 584 artists/creators. This sounds strange in a profession we so frequently advocate as not being authorial and driven by the client's necessities. If design benefits from teamwork, why do only $2.5 \%$ of examples come from companies? And why bother separating individual and corporate work by the same designer (e.g. Gert Dumbar from Dumbar Studio and Paula Scher from Pentagram)?

Clients - a vital aspect in the development of any communication process - also don't matter.

\section{References}

Baxandall, M., 1991. Painting and experience in the fifteenth-century Italy. New Edition 2nd ed., Oxford: Oxford University Press.

Dilnot, C., 1989. The state of design history, part I: mapping the field. In V. Margolin, ed. Design Discourse. History.Theory.Criticism. Chicago: The University of Chicago Press, pp. 213-232.

Drucker, J. \& McVarish, E., 2009. Graphic design history: a critical guide, New Jersey: Pearson, Prentice Hall.

Eskilson, S.J., 2007. Graphic design, a new history, London: Laurence King.

Fallan, K., 2010. Design History, Understanding Theory And Method, Oxford: Berg Publishers. Hollis, R., 2002. Graphic Design: A Concise History 2nd ed., London: Thames \& Hudson. Meggs, P. \& Purvis, A., 2011. Meggs' History of Graphic Design 5th ed., Hoboken: Wiley. Walker, J., 1989. Defining the object of study. In J. Walker, ed. Design history or the history of design. London: Pluto Press, pp. 22-36.

Whitehouse, D., 2009. The state of design history as a discipline. In H. Clark \& D. Brody, eds. Design studies: a reader. Oxford: Berg Publishers, pp. 54-63. 